\title{
Corrigendum
}

\section{The influence of gender on clinical and social characteristics of patients at psychosis onset: a report from the Psychosis Incident Cohort Outcome Study (PICOS) - Corrigendum}

M. Bertani ${ }^{1}$, A. Lasalvia ${ }^{*}$, C. Bonetto ${ }^{1}$, S. Tosato $^{1}$, D. Cristofalo ${ }^{1}$, S. Bissoli ${ }^{1}$, K. De Santi ${ }^{1}$, R. Mazzoncini ${ }^{1}$, L. Lazzarotto ${ }^{1}$, M. Santi ${ }^{2}$, A. Sale ${ }^{3}$, D. Scalabrin ${ }^{4}$, M. Abate ${ }^{5}$, M. Tansella ${ }^{1}$, M. Ruggeri ${ }^{1}$, on behalf of the PICOS-Veneto Group

doi:10.1017/S0033291711001991. Published online by Cambridge University Press, 14 October 2011.

The author affiliations appear incorrectly in the above paper for which the authors apologize. The correct version is given below:

M. Bertani ${ }^{1}$, A. Lasalvia ${ }^{1}$, C. Bonetto ${ }^{1}$, S. Tosato $^{1}$, D. Cristofalo ${ }^{1}$, S. Bissoli ${ }^{1}$, K. De Santi ${ }^{1}$, R. Mazzoncini ${ }^{1}$, L. Lazzarotto ${ }^{1}$, M. Santi ${ }^{2}$, A. Sale ${ }^{3}$, D. Scalabrin ${ }^{4}$, M. Abate ${ }^{5}$, M. Tansella ${ }^{1}$, M. Ruggeri ${ }^{1}$, on behalf of the PICOS-Veneto Group

${ }^{1}$ Department of Public Health and Community Medicine, Section of Psychiatry and Clinical Psychology, University of Verona, Verona, Italy

${ }^{2}$ Casa di Cura 'Villa Santa Giuliana', Verona, Italy

${ }^{3}$ Department of Mental Health, NHS Local Health Authority Vicenza, Italy

${ }^{4}$ Department of Mental Health, NHS Local Health Authority Cittadella (PD), Italy

${ }^{5}$ Casa di Cura 'Villa Santa Chiara', Verona, Italy

\section{Reference}

Bertani M, Lasalvia A, Bonetto C, Tosato S, Cristofalo D, Bissoli S, De Santi K, Mazzoncini R, Lazzarotto L, Santi M, Sale A, Scalabrin D, Abate M, Tansella M, Ruggeri M, on behalf of the PICOS-Veneto Group (2011). The influence of gender on clinical and social characteristics of patients at psychosis onset: a report from the Psychosis Incident Cohort Outcome Study (PICOS). Psychological Medicine. doi:10.1017/S0033291711001991. 